\title{
CALIBRATION AND VALIDATION OF A NUMERICAL CURING MODEL USING AS4/8552 ASYMMETRIC LAMINATED COMPOSITE PLATES
}

\author{
$\underline{\text { T.P.A. Koenis }}^{1 *}$, N. van Hoorn ${ }^{1}$, W.M. van den Brink ${ }^{1}$ \\ ${ }^{1}$ Royal Netherlands Aerospace Centre \\ *Tim.Koenis@nlr.nl
}

During manufacturing of composite materials residual stresses and deformations can result in distortion of the final part. In aerospace manufacturing the use of shimming caused by part distortions during assembly should be minimized. The prediction and minimization of the distortion is even more critical when building on existing parts, e.g. for a repair, as the added material has to conform to the original structure. To predict this distortion due to curing of thermoset carbon-matrix composites a numerical modelling method is employed. This method includes the cure kinetics, the Cure Hardening Instantaneously Linear Elastic (CHILE) pseudoviscoelastic model [1], and the homogenisation of laminae properties employing the Composite Cylinder Assemblage (CCA) model [2]. This method is implemented in ABAQUS by using the USDFLD and EXPAN subroutines. A prominent issue when accurately modelling the distortion due to curing is the absence of accurate material parameters. To this end, a calibration method is proposed to estimate unknown parameters for the numerical curing model (e.g., the thermal expansion and chemical shrinkage coefficients of the resin). In an experimental campaign AS4/8552 plates have been manufactured with a $\left[90_{\mathrm{n}} 0_{\mathrm{m}}\right]$ asymmetrical layup. The numerical model is calibrated to match the deformation of the asymmetrical plates. In addition, an experiment is performed where the plates have been reheated. At the elevated temperature this leads to a reduction in deformation. With this approach, the effects of thermal expansion have been isolated from the chemical induced deformation, which facilitates direct calibration of the coefficients of thermal expansion. After calibration, the numerical modelling approach is validated using additional asymmetric plates and more complex shaped parts.

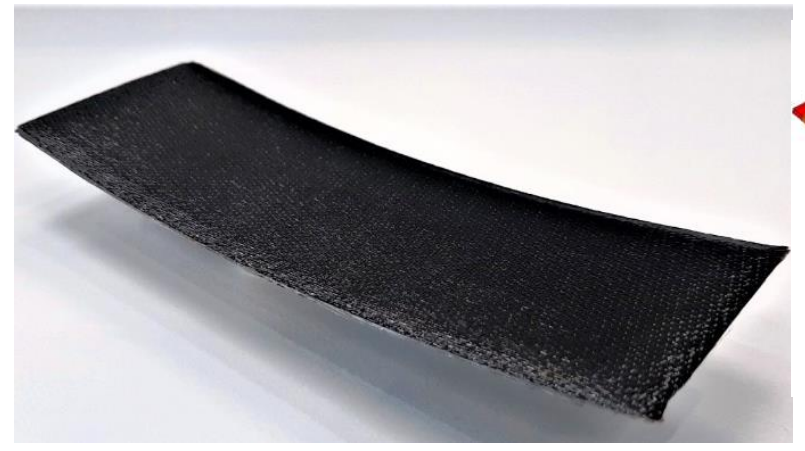

(a)

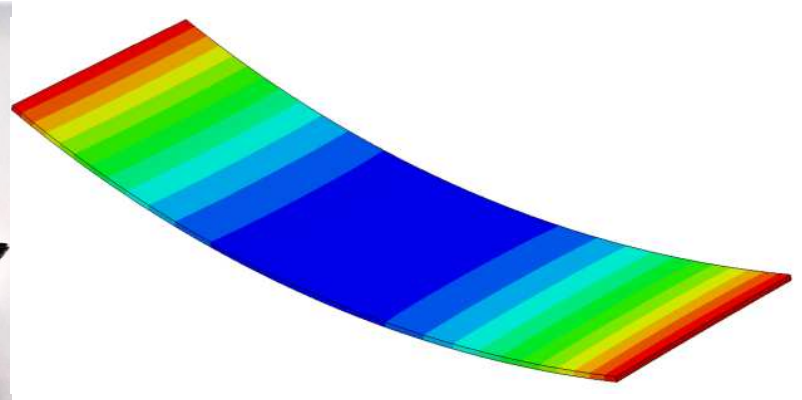

(b)

Figure 1. Deformation of an asymmetrical plate obtained from (a) experiments and (b) predicted by the numerical curing model.

\section{References}

[1] Johnston A, Vaziri R, Poursartip A. A plane strain model for process-induced deformation of laminated composite structures. Journal of Composite Materials 2001; 35 (16); 14351469

[2] Hashin, Z. Analysis of composite materials - a survey. Journal of Applied Mechanics 1983; $50 ; 481-505$ 